\title{
CONSTRAINTS FACED BY THE FARMERS IN ADOPTION OF IPM IN CAULIFLOWER CULTIVATION
}

\section{NIDHI \& B. N. KALSARIYA}

Research Scholar and Assistant professor at Department. of Agricultural Extension, JAU, Junagadh, Gujarat, India

IPM refers to an ecological approach in pest management, in which, all available necessary techniques are consolidated in a unified programme, so that, pest population can be managed in such a manner that economic damage is avoided and adverse side effects are minimized. The goal of IPM is to control population of the pest below level that result in economic damage. Ideally, this is achieved through the integration of all suitable control techniques in a compatible manner. The present study was conducted in Badgaon and Girwa tehsils of Udaipur district of Rajasthan. Four villages from each selected tehsil were taken and 12 respondents were selected randomly from each selected village for the study. Data were collected through pre structured interview schedule. It was found that inadequate demonstrations on IPM technology, lack of knowledge about pest life cycle and their infestation on cauliflower, lack of trainings on IPM technologies, non-availability of trichoderma at local level, supply of inferior quality of bio fertilizers were important constraints perceived by the farmers in adoption of IPM in cauliflower cultivation.
\end{abstract}

KEYWORDS: IPM, Cauliflower, Trichoderma \& Biofertilizers

Received: May 30, 2017; Accepted: Jun 20, 2017; Published: Jul 06, 2017; Paper Id.: IJBRAUG20172

\section{INTRODUCTION}

Cauliflower (Brassica oleracea var. botrytis) is one of the most important as well as popular winter vegetable crops, which is grown throughout the country. In India, cauliflower is cultivated in 402.20 thousand hectare area with a total production of 7886.73 thousand million tonnes in 2012-13. (Source: www.nhb.gov.in).The total area under cauliflower cultivation in Rajasthan is 10126 hectares with a total production of 397981 tonnes in 2012-13. (Source: Directorate of Horticulture, Pant Krishi Bhawan, Jaipur).

Integrated Pest Management is one of such systematic approach, which emphasizes not only the reduction in use of pesticides and keeping below the level of pest causing economic injury, but also it facilitates the use of cultural, mechanical, botanical, biological and chemical methods of control in an integrated manner and restores ecological balance for sustainable agriculture

IPM is a knowledge-based technology. It involves integration of different methods of disease and pest management to manage an important disease like club rot, black rot and black tip and pests like Diamond back moth, tobacco caterpillar and cabbage semi lopper etc. of a particular crop to manage all diseases and pests in a particular cropping system. Under IPM, use of chemical pesticides is discouraged but not totally banned. IPM modules are area specific. They take into consideration not only diseases and insect pests but also availability of inputs. Most of the modules include too many practices, which usually discourage the farmers. They are not ready to invest their entire 
energy in pest management alone. Therefore, it is important to develop modules involving few critical interventions. Uses of resistant varieties are most important input of any IPM module. The use of pesticides should be avoided as much as possible. However, need based and judicious use of pesticides is advocated under IPM. Wherever, available use of environmentally safe pesticide should be preferred.

But, generally farmers are using pesticides for controlling insect-pests in cauliflower, which are harmful for human health. So, there is essential to give a focus on IPM to maintain the nutritional level and sustainability in production of vegetables. However, inappropriate use of chemical pesticide create problem of ecological imbalance, environmental pollution and health hazards. The development of pesticide resistance also contributed to the loss of beneficial insects and micro-organisms. Even the fertility of the soil is adversely affected due to repeated applications of soil pesticides. Thus, excess use of pesticides and its residues has created numerous side effects. Therefore, integrated pest management techniques are beneficial for controlling insect-pests as well as human health. Looking to the importance of IPM in cauliflower cultivation, the present study was conducted.

\section{MATERIALS AND METHODS}

The present study was conducted in the purposively selected Udaipur district of Rajasthan. There are total eleven tehsils in Udaipur district of Rajasthan, out of which, two tehsils namely Badgaon and Girwa were selected on the basis of maximum area under cultivation of cauliflower. Further, a comprehensive list of all the major cauliflower growing villages was prepared in consultation with the personnel of Revenue and Agriculture Department from the identified tehsils. Four villages from each selected tehsil were taken on the basis of maximum area under cauliflower cultivation. For selection of respondents, comprehensive list of cauliflower growers was prepared with the help of village patwari and Agriculture Supervisor of respective villages. From the list so prepared, 12 respondents were selected randomly from each selected village. Thus, in all 96 farmers were included in the sample of the study. Data were collected through prestructured interview schedule.

\section{RESULTS AND DISCUSSION}

The constraints perceived by the cauliflower growers in adoption of IPM were identified and same have been presented in subsequent tables:

To get an overview of constraint level, the respondents were divided into three groups viz., (i) low level constraint (<42.73) (ii) medium level constraint (42.73 to 57.97) and high level constraint (> 57.97). The groups were formulated on the basis of calculated mean and standard deviation of the adoption scores obtained by the respondents. The results are presented in the Table 1.

Table 1: Distribution of Respondents According to their Constraint Level in Adoption of IPM in Cauliflower Cultivation $\mathbf{n = 9 6}$

\begin{tabular}{|c|l|c|c|c|c|c|c|}
\hline \multirow{2}{*}{ S.No. } & \multirow{2}{*}{ Constraint Level } & \multicolumn{2}{|c|}{ Frequency } & \multicolumn{2}{c|}{ Percentage } & \multicolumn{2}{c|}{ Total } \\
\cline { 3 - 7 } & & Badgaon & Girwa & Badgaon & Girwa & F & P \\
\hline 1. & Low $(<42.63)$ & 12 & 10 & 25 & 20.83 & 22 & 22.92 \\
\hline 2. & Medium (42.64 to 58.01) & 22 & 23 & 45.83 & 47.92 & 45 & 46.88 \\
\hline 3. & High $(>58.01)$ & 14 & 15 & 29.17 & 31.25 & 29 & 30.21 \\
\hline & Total & 48 & 48 & 100 & 100 & 96 & 100 \\
\hline
\end{tabular}

$\mathrm{F}=$ frequency, $\mathrm{P}=$ per cent 
The data in Table 1 reveal that out of 96 respondents, majority of respondents 46.88 per cent fell in medium level of adoption group whereas, 30.21 per cent cauliflower growers were observed in the high level adoption group and remaining per cent respondents were possessed 22.92 per cent low level of adoption about Integrated Pest Management in cauliflower cultivation.

Analysis of table further reveals that 25 and 20.83 per cent respondents were observed in low constraints level group in Badgaon and Girwa tehsils, respectively. While, 45.83 and 47.92 per cent respondents were observed in medium constraints level group in Badgaon and Girwa tehsils respectively. Whereas, 29.17 and 31.25 per cent respondents were observed in high constraints level group in Badgaon and Girwa tehsils respectively.

The similar findings had been reported by Vashishtha (2007) who revealed that 53.75 per cent respondents were in the medium constraints group and 23.75 per cent of total respondents were in high constraint group and 22.50 per cent respondents were observed in the low constraint group.

It is evident from the data incorporated in Table 2 that inadequate demonstrations on IPM technologies was the most severe constraint encountered by majority of the cauliflower growers with mean score 87.15 and was ranked first by cauliflower growers. Besides, lack of knowledge about pest's life cycle and their infestation stages was severe constraints perceived by the cauliflower growers with 86.11 mean score and was ranked second by cauliflower growers.

Table 2: Constraints Perceived by the Cauliflower Growers in Adoption of IPM n = 96

\begin{tabular}{|c|l|c|c|}
\hline S.No. & \multicolumn{1}{|c|}{ General Constraints } & MPS & Rank \\
\hline 1. & Lack of knowledge about pests' life cycle and their infestation on cauliflower & 86.11 & 2 \\
\hline 2. & Lack of technical guidance regarding ETL assessment & 69.79 & 18 \\
\hline 3. & Improper monitoring of fields for pest surveillance & 73.96 & 13 \\
\hline 4. & Non-availability of suitable implement for field sanitation and deep ploughing & 70.49 & 17 \\
\hline 5. & Lack of knowledge about crop rotation & 57.29 & 23 \\
\hline 6. & Lack of knowledge about improved varieties of cauliflower & 53.13 & 24 \\
\hline 7. & Non- availability of high yielding varieties of cauliflower & 57.64 & 22 \\
\hline 8. & High cost of high yielding varieties of cauliflower & 65.28 & 21 \\
\hline 9. & Lack of technical guidance for seed treatment & 70.83 & 15.5 \\
\hline 10. & Non-availability of pesticide and biofertilizers for seed treatment & 69.44 & 19 \\
\hline 11. & Supply of inferior quality of biofertilizers & 79.51 & 5.5 \\
\hline 12. & Lack of knowledge about intercropping & 66.67 & 20 \\
\hline 13. & Lack of knowledge about botanical pesticide & 79.17 & 7.5 \\
\hline 14. & Non-availability of neem cake at local level & 77.08 & 11 \\
\hline 15. & Lack of skill in preparing NSKE solution & 76.04 & 12 \\
\hline 16. & Lack of knowledge about Bt biopesticide & 77.78 & 9 \\
\hline 17. & Lack of skill about biopesticide application in cauliflower & 77.43 & 10 \\
\hline 18. & Non-availability of trichoderma at local market & 84.03 & 4 \\
\hline 19. & Lack of knowledge about ETL for using chemical pesticide & 72.57 & 14 \\
\hline 20. & Lack of proper knowledge about insect- pests' damaging stages & 79.51 & 5.5 \\
\hline 21. & Lack of trainings on IPM technologies & 84.72 & 3 \\
\hline 22. & Inadequate demonstrations on IPM technologies & $\mathbf{8 7 . 1 5}$ & $\mathbf{1}$ \\
\hline 23. & Lack of subsidy from government on IPM control measures. & 79.17 & 7.5 \\
\hline 24. & Lack of awareness about hazardous and residual effect of chemical pesticides & 70.83 & 15.5 \\
\hline & &
\end{tabular}

MPS = Mean Per cent Score

Analysis of data indicates that constraint about lack of knowledge about improved varieties of cauliflower with 53.13 mean score which was assigned last rank by the cauliflower growers. 
The findings are in agreement with the findings of Goyal (2006), who had reported that lack of knowledge and skill in preparing NSKE solution at home level followed by lack of technical guidance were main constraints perceived by farmers in adoption of botanical practices of IPM in chickpea.

Table 3: Significance of Difference in the Constraints of Farmers of Selected Tehsils in Adoption of IPM in Cauliflower Cultivation

In order to find out the significance of difference between the farmers of selected tehsils with respect to the constraints possessed by them, 'Z' test was applied. For this purpose, the following hypotheses were tested and results of which are presented in Table 3.

$\mathbf{N H}_{01}$ : There is no significant difference between the farmers of selected tehsils with respect to constraints in adoption of IPM practices in cauliflower cultivation.

$\mathbf{R H}_{\mathbf{1}}$ : There is significant difference between the farmers of selected tehsils with respect to constraints in adoption of IPM practices in cauliflower cultivation.

Table 3: Significance of Difference in the Constraints of Farmers of Selected Tehsils in Adoption of IPM in Cauliflower Cultivation

\begin{tabular}{|c|l|c|c|c|}
\hline S.No & \multicolumn{1}{|c|}{ Category Of Sample } & Mean & S.D. & 'Z' Value \\
\hline 1. & Respondents of Badgaon tehsil & 51.96 & 7.67 & $2.09^{*}$ \\
\hline 2. & Respondents of Girwa tehsil & 48.75 & 7.30 & \\
\hline
\end{tabular}

* Significant at 5 per cent level of significance

The calculated value of ' $Z$ ' (2.09) is greater than its tabulated value at 5 per cent level of significance, this call for rejection of $\mathrm{NH}_{01}$ and leads to conclusion that there was significant difference between the farmers of both tehsils with respect to constraints in adoption of IPM practices in cauliflower cultivation.

\section{CONCLUSIONS}

From the above discussion, it can be concluded that inadequate demonstrations on IPM technology, lack of knowledge about pests' life cycle and their infestation on cauliflower, lack of trainings on IPM technologies, nonavailability of trichoderma at local market and supply of inferior quality of biofertilizers were important constraints perceived by the cauliflower growers in the adoption of IPM technology in cauliflower cultivation. It was further noted that there was a significant difference between the respondents of selected tehsils, with respect to constraints in adoption of IPM practices in cauliflower cultivation.

\section{REFERENCES}

1. Goyal, M.C. 2006. Adoption of Integrated Pest Management in chickpea production in Kota district of Rajasthan. Ph.D. thesis submitted to MPUAT, Udaipur.

2. Vashishtha, U. 2007. Farmers' response towards Pigeon-pea (Cajanus Cajan L.) cultivation in Tribal area of Udaipur district of Rajasthan. M.Sc. (Ag.) thesis submitted to Maharana Pratap University of Agriculture and Technology, Udaipur. 